\title{
Wanderlust into (Y)our Past: Mediating Intimacy for Prosocial Co-existing with Your Loved One in Home Quarantine
}
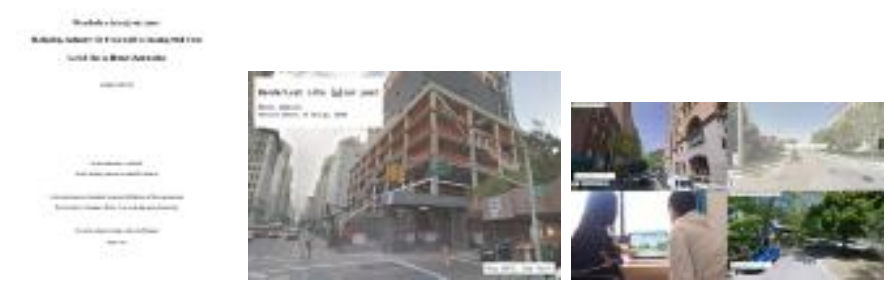

\section{Related Collection}

2020 (PC020402.16) $\rightarrow$ Parsons School of Design MFA Design and Technology program theses

\section{Description}

In this paper, I present a web-based experience named Wanderlust into (y)our past, which aims to mediate a bond with a partner, family member, and loved ones. Due to the COVID-19 pandemic in 2020, couples and families are learning how to co-exist healthily in quarantined life where they live together all the time in a confined space. Wanderlust into (y)our past takes them together to a virtual time travel to the places where they have been in the past and nudges them to share personal memories. Through these interpersonal dialogues of the past, this system encourages them to consider each other and take collaborative and prosocial actions towards the new normal in the post-pandemic. This paper describes backgrounds, approaches, ongoing functional prototype, and a future direction.

Creator Keywords:

web interaction; mediating intimacy; interaction design; Google Street View API; COVID-19; home quarantine; memory sharing; family bond

\section{Date}

May 32020

\section{Related people}

Masaki Iwabuchi (designer)

Jess Irish (thesis advisor)

Danielle A. Jackson (thesis advisor)

\section{Related Repository}


Parsons Institutional Collections

\section{Use Restrictions}

In accordance with The New School's Intellectual Property Rights Policy, copyright is held by each thesis' respective author. The responsibility to secure copyright permission rests with the user.; http://rightsstatements.org/vocab/lnC/1.0/

\section{Identifier}

PC020402_2020_iwabm186 